\title{
Composição físico-química e qualidade sensorial de café conilon produzido no Estado do Espírito Santo e submetido a diferentes formas de processamento
}

\section{Physico-chemical composition and sensory quality of conilon coffee produced in Espírito Santo State and submitted to different processing forms}

\author{
Tarcísio Lima Filho ${ }^{1}$; Suzana Maria Della Lucia ${ }^{2 *}$; \\ Sérgio Henriques Saraiva²; Marco Antônio Sartori ${ }^{3}$
}

\section{Resumo}

\begin{abstract}
Apesar de o estado do Espírito Santo ser o maior produtor de café conilon brasileiro, pouco se sabe sobre a composição físico-química e características sensoriais desse café submetido a diferentes formas de processamento. Sendo assim, o objetivo deste trabalho foi realizar a caracterização físico-química e sensorial do café conilon capixaba submetido a três formas de processamento. A colheita foi realizada selecionando-se apenas grãos cereja, que foram submetidos a três formas de processamento (via seca, via úmida sem fermentação ou via úmida com fermentação). A análise sensorial foi realizada por dois julgadores classificadores profissionais. Em amostras de café cru e torrado foram realizadas análises físico-químicas de umidade, $\mathrm{pH}$ e acidez titulável total e o extrato aquoso foi determinado apenas para amostras de café torrado. As formas de processamento e tipos de grãos apresentaram médias de $\mathrm{pH}$ e acidez estatisticamente iguais. Os cafés natural e descascado apresentaram maiores teores de extrato aquoso. Na classificação sensorial, todas as amostras apresentaram boa nota global. A utilização de matéria-prima dentro dos padrões de qualidade, o processamento de apenas grãos cereja e a realização adequada das etapas pós-colheita possibilitam a obtenção de uma bebida com boa classificação sensorial e sem alterações de $\mathrm{pH}$ e acidez, independentemente da forma de processamento utilizada. É possível obter bebidas dentro dos padrões de qualidade utilizando o processamento via seca, processamento menos custoso que os demais.
\end{abstract}

Palavras-chave: Coffea canephora Pierre, café natural, café descascado, café despolpado, café conilon

\begin{abstract}
Espirito Santo State is the largest producer of conilon coffee in Brazil. However, there is a lack of information about physico-chemical composition and sensory characteristics of this coffee submitted to different processing forms. Therefore, the objective of this work was to investigate physico-chemical and sensory characteristics of the Espirito Santo conilon coffee submitted to three forms of processing. The harvest was performed selecting only cherry grains, which were submitted to three forms of processing (dry process, semi dry process or wet process). Sensory analysis was performed by two professional
\end{abstract}

\footnotetext{
1 Mestre em Ciência e Tecnologia de Alimentos, Centro de Ciências Agrárias, Universidade Federal do Espírito Santo, CCA/ UFES, Alegre, ES. E-mail: tarcisiolimaf@yahoo.com.br

2 Profs. Drs. do Programa de Pós-Graduação em Ciência e Tecnologia de Alimentos, CCA/UFES, Alegre, ES. E-mail: smdlucia@ yahoo.com.br; sergio@cca.ufes.br

Prof. Dr. do Dept ${ }^{\circ}$ de Engenharia de Alimentos, CCA/UFES, Alegre, ES. E-mail: marcosartori10@yahoo.com.br

* Autor para correspondência
} 
classifiers. Analysis of moisture, $\mathrm{pH}$ and titratable acidity were determined in samples of raw and roasted coffee and aqueous extract were determined in samples of roasted coffee. The processing forms and types of grains did not differ in terms of $\mathrm{pH}$ and acidity. Natural and peeled coffee showed higher levels of aqueous extract. In sensory classification, all samples showed good overall evaluation. The use of raw material within the quality standards, grains of cherry type and the proper conduction of post-harvest stages allow the obtainment of a beverage with good sensory ratings and without changes in $\mathrm{pH}$ and acidity regardless the processing form used. Therefore, it is possible to obtain good quality beverages using dry processing, which is less expensive than the other types of coffee processing.

Key words: Coffea canephora Pierre, natural coffee, peeled coffee, washed coffee, conilon coffee

\section{Introdução}

Com o fim da intervenção do governo brasileiro sobre o preço do café, os produtores e torrefadores puderam direcionar maiores investimentos na obtenção de bebidas de melhor qualidade e, assim, satisfazer as exigências dos consumidores (MENDES, 2005). Com esse objetivo foram desenvolvidas novas tecnologias no processamento do café.

Atualmente, o processamento do café pode ser realizado por via seca ou por via úmida. No preparo por via seca o café é seco sem a retirada da casca, dando origem ao café natural. No processamento via úmida pode-se obter o café descascado ou o café despolpado. Para se obter o café descascado, retirase, mecanicamente, apenas a casca do fruto e, para o café despolpado, retira-se a casca, mecanicamente, e a mucilagem, por processo fermentativo (PIMENTA, 2003).

A fim de investigar os fatores, tais como as formas de processamento, que afetam a qualidade final da bebida, podem-se utilizar como instrumentos de medida as características físico-químicas e sensoriais do café. A complexa composição físicoquímica do café é responsável pela aparência do grão torrado e o sabor e aroma característicos da bebida, isto é, ela define a qualidade final da bebida (PIMENTA, 2003) e a avaliação sensorial é o meio mais rápido, simples e direto de detectar as causas de defeitos na qualidade dos alimentos (DELLA LUCIA et al., 2009).

Ainda que existam vários estudos em desenvolvimento objetivando a análise da composição físico-química do café brasileiro, ainda pouco se sabe sobre a composição do café conilon produzido no Estado do Espírito Santo e suas alterações devido às diferentes formas de processamento. Este tipo de estudo torna-se de fundamental importância, já que esta composição é determinada, dentre outros fatores, por sua região de origem, genética, clima, altitude, sistema de cultivo e formas de processamento (PIMENTA, 2003). Além disso, o fato de o Espírito Santo ser o maior produtor nacional de café conilon e a necessidade de o setor cafeeiro capixaba aprofundar conhecimentos sobre a composição físico-química e sensorial do conilon e sobre formas de processamento que melhorem a qualidade desse produto, acentuam ainda mais a importância desse estudo.

Sendo assim, teve-se como objetivo realizar a caracterização físico-química e sensorial do café conilon produzido no estado do Espírito Santo submetido a três formas de processamento, a fim de verificar possíveis alterações, causadas pela forma de processamento, que possam interferir na qualidade final da bebida.

\section{Material e Métodos}

\section{Material}

Os grãos de café utilizados neste estudo foram da espécie Coffea canephora Pierre da safra 2009/2010, provenientes da Fazenda Experimental de Venda Nova do Imigrante-ES do INCAPER Instituto Capixaba de Pesquisa, Assistência Técnica e Extensão Rural, local onde foram, também, realizadas as etapas de colheita, processamento, secagem e beneficiamento do café conilon. 


\section{Preparo das amostras}

A colheita foi realizada em peneira e de forma seletiva, colhendo apenas os grãos cereja. Para cada repetição, o café conilon foi colhido, lavado e dividido em três lotes. Cada lote de café conilon foi submetido a uma forma de processamento. Um lote foi processado por via seca, processamento em que o café foi levado diretamente para o terreiro suspenso para etapa de secagem, constituindo a parcela de café natural. Em outro lote, submetido ao processamento via úmida sem fermentação, retirou-se, mecanicamente, apenas a casca dos grãos de café, dando origem ao café descascado. O terceiro lote de café foi processado via úmida com fermentação, processamento em que foi retirada a casca dos frutos, utilizando descascador mecânico, seguida de fermentação da mucilagem do café por um período de $20 \mathrm{~h}$ e posterior lavagem dos grãos, dando origem ao café despolpado. Após a etapa de processamento os lotes passaram pela etapa de secagem em terreiro de tela suspensa. Em seguida, foi realizado o beneficiamento do café, etapa em que foram retiradas impurezas dos lotes e retirada a casca e pergaminho do café natural, dando origem ao café cru (PIMENTA, 2003).

Os processos de torrefação e moagem do café foram realizados no Laboratório de Operações Unitárias e as análises físico-químicas no Laboratório de Química de Alimentos, ambos do Centro de Ciências Agrárias da Universidade Federal do Espírito Santo, na cidade de Alegre - ES.

Para cada lote submetido a uma forma de processamento, uma alíquota de $1 \mathrm{~kg}$ foi separada para posterior análise sensorial. Para obtenção do grão torrado, uma amostra de $200 \mathrm{~g}$ de café cru foi torrado em torrador/moedor de prova a gás, marca Pinhalense, apresentando perda de matéria seca de aproximadamente $7 \%$ e coloração referente ao ponto \#55 do disco de cores Agtron-SCAA, caracterizando, assim, torra média (ABIC, 2012). Outra amostra, de $200 \mathrm{~g}$ de café cru, foi congelada a $-20^{\circ} \mathrm{C}$ para facilitar a moagem. Tanto os grãos crus quanto os torrados foram moídos em moinho de facas tipo Willy, marca Solab, com peneiras de saída com furos de 20 mesh.

\section{Análises físico-químicas}

As análises físico-químicas de umidade, $\mathrm{pH}$ e acidez titulável total foram realizadas nos grãos crus e torrados das três formas de processamento e o teor de extrato aquoso foi determinado apenas nos grãos torrados.

\section{Umidade}

A umidade dos grãos crus foi determinada por analisador de umidade e impureza modelo G650, marca Gehaka Agri.

A determinação da umidade dos grãos torrados foi realizada pelo método de secagem direta em estufa (IAL, 2008). Uma alíquota de $10 \mathrm{~g}$ de café moído foi submetida à secagem em estufa a $105^{\circ} \mathrm{C}$ até peso constante. O resultado foi expresso em porcentagem de umidade $(\mathrm{m} / \mathrm{m})$.

$p H$

Para análise de $\mathrm{pH}$ foram pesados $5 \mathrm{~g}$ da amostra de café moído e adicionados $50 \mathrm{~mL}$ de água destilada, agitando-se por 1 hora em agitador magnético modelo 114, marca Nova Ética. Em seguida, o pH foi medido por potenciômetro, à temperatura ambiente, utilizando pHmetro modelo mPA-210, marca Tecnopon (IAL, 2008).

\section{Acidez titulável total}

O mesmo extrato utilizado na medição do $\mathrm{pH}$ foi utilizado para medir a acidez titulável total das amostras. Como a coloração do café impossibilita a visualização do ponto de viragem, quando utilizada solução indicadora, a análise foi realizada com auxílio de pHmetro. A medição foi realizada por titulação com $\mathrm{NaOH} 0,1 \mathrm{~N}$ até $\mathrm{pH}$ 
8,2 , sob temperatura ambiente. Os resultados foram expressos em acidez em solução molar por $100 \mathrm{~g}$ (IAL, 2008).

\section{Extrato aquoso}

Uma alíquota de $2 \mathrm{~g}$ de café moído foi dissolvida em $200 \mathrm{~mL}$ de água destilada. Em seguida, a solução foi submetida à extração a quente, sob temperatura de ebulição, durante uma hora. $\mathrm{O}$ extrato passou por uma etapa de filtragem e $50 \mathrm{~mL}$ do filtrado foram secos em banho-maria a $70^{\circ} \mathrm{C}$ (IAL, 2008). $\mathrm{O}$ resultado foi expresso em porcentagem de extrato aquoso $(\mathrm{m} / \mathrm{m})$.

\section{Análise sensorial}

A avaliação sensorial (prova de xícara) foi realizada por dois julgadores e classificadores profissionais (experts) da Cooperativa dos Cafeicultores das Montanhas do Espírito Santo Pronova em Venda Nova do Imigrante-ES.

O preparo da bebida foi realizado seguindo as recomendações da Specialty Coffee Association of America (SCAA, 2009) e a classificação sensorial foi baseada na Metodologia de Classificação de Café Conilon do Centro de Desenvolvimento Tecnológico do Café (CETCAF), em parceria com a Associação Brasileira da Indústria de Café (ABIC) (CETCAF, 2006).

Para cada forma de processamento, uma amostra de $1 \mathrm{~kg}$ de café conilon foi torrada, obtendo ponto de torra referente ao ponto 65 no Disco Agtron, rapidamente resfriada e estocada em local fresco e escuro durante o período de 9 horas. Após esse período, foi realizada a moagem da amostra e imediatamente preparada a infusão com água (na temperatura de aproximadamente $93^{\circ} \mathrm{C}$ ) na concentração de $5,5 \mathrm{~g}$ de grãos de café por 100 $\mathrm{mL}$ de água. Foram preparadas cinco xícaras por amostra, que foram codificadas e avaliadas quanto aos atributos de gosto doce (leve, moderado ou forte), gosto conilon (suave, médio, intenso ou gosto estranho), acidez (baixa, média, alta ou excessiva), adstringência (maior ou menor), corpo (pouco, médio ou muito), pureza (informa a ocorrência de sabores e, ou odores estranhos, podendo ser classificado como: limpo, gosto fumaça, gosto químico, entre outros) e qualidade global (nota global levando em consideração todas as características sensoriais da amostra, variando de 0 a 10).

A classificação sensorial foi realizada de forma descritiva e a nota da qualidade global foi apresentada juntamente com seus desvios.

\section{Planejamento experimental e análise estatística}

Para as análises físico-químicas foi utilizado o delineamento experimental inteiramente casualizado (DIC), com três repetições, em que o tratamento testado foi o tipo de processamento pós colheita, para o grão cru e para o grão torrado. Os resultados obtidos foram submetidos à análise de variância (ANOVA) e nos casos em que ocorreu diferença significativa entre os tratamentos foi aplicado o teste de Tukey a $5 \%$ de significância. A análise estatística foi realizada utilizando o software SAEG (Sistema para Análises Estatísticas) versão 9.1 (RIBEIRO JÚNIOR, 2001).

\section{Resultados e Discussão}

O teor de umidade encontrado no grão cru (Tabela 1) está de acordo com a Instrução Normativa $n^{\circ} 8$, de 11 de junho de 2003 (BRASIL, 2003), não excedendo o limite máximo de tolerância, para café cru, de $12,5 \%$. De acordo com a Instrução Normativa $\mathrm{n}^{\circ}$ 16, de 24 de maio de 2010 (BRASIL, 2010), o café torrado deve conter um teor de umidade de, no máximo, $5 \%$. As amostras de café torrado analisadas estão dentro do padrão estipulado (Tabela 1). 
Tabela 1. Médias e desvios-padrão dos valores das variáveis físico-químicas estudadas para as diferentes formas de processamento e tipo de grão(1).

\begin{tabular}{|c|c|c|c|c|}
\hline Variáveis & Grão & Natural & Descascado & Despolpado \\
\hline \multirow{2}{*}{ Umidade $(\% \mathrm{~m} / \mathrm{m})$} & Cru & $11,80 \pm 0,1$ & $10,90 \pm 0,3$ & $10,90 \pm 0,2$ \\
\hline & Torrado & $1,49 \pm 0,2$ & $2,01 \pm 0,4$ & $1,74 \pm 0,3$ \\
\hline \multirow{2}{*}{$\mathrm{pH}$} & Cru & $(5,81 \pm 0,02) \mathrm{a}$ & $(5,79 \pm 0,04) \mathrm{a}$ & $(5,80 \pm 0,01) \mathrm{a}$ \\
\hline & Torrado & $(5,40 \pm 0,08) \mathrm{a}$ & $(5,27 \pm 0,04) \mathrm{a}$ & $(5,35 \pm 0,09) \mathrm{a}$ \\
\hline \multirow{2}{*}{ Acidez titulável total ${ }^{(2)}$} & Cru & $(8,51 \pm 0,13) \mathrm{a}$ & $(8,81 \pm 0,25) \mathrm{a}$ & $(8,95 \pm 0,24) \mathrm{a}$ \\
\hline & Torrado & $(11,40 \pm 0,34) \mathrm{a}$ & $(11,84 \pm 0,48) \mathrm{a}$ & $(10,95 \pm 0,59) \mathrm{a}$ \\
\hline Extrato aquoso $(\% \mathrm{~m} / \mathrm{m})$ & Torrado & $(26,50 \pm 2) \mathrm{a}$ & $(26,40 \pm 1) \mathrm{a}$ & $(19,08 \pm 2) b$ \\
\hline
\end{tabular}

(1) Médias com letras iguais, na horizontal, não diferem entre si pelo teste de Tukey, a $5 \%$ de probabilidade. ${ }^{(2)}$ Acidez titulável total expressa em acidez em solução molar por $100 \mathrm{~g}$.

Fonte: Elaboração dos autores.

Os valores de $\mathrm{pH}$ do café cru encontrados (Tabela 1) são compatíveis com a faixa de $\mathrm{pH}$ encontrado por Salva (2007), de 5,7 a 5,85. Jacintho (2002) e Salva (2007) também não encontraram diferença significativa entre as médias de $\mathrm{pH}$ para amostras de conilon cru submetidos a diferentes formas de processamento.

Conforme a OIC (1992), os valores recomendados de $\mathrm{pH}$ devem estar entre 5,31 e 5,61, para amostras de cafés comerciáveis. Clifford (1985) afirma que a faixa de $\mathrm{pH}$ ideal para café conilon está entre 5,0 e 5,8. Mais recentemente, Balzer (2001) foi mais rigoroso e citou a faixa de $\mathrm{pH}$ de 5,25 a 5,4 como sendo a ideal para café conilon. Os valores de $\mathrm{pH}$ encontrados estão dentro das faixas de $\mathrm{pH}$ citados por Clifford e Balzer e apenas o $\mathrm{pH}$ do café torrado despolpado encontrou-se fora da faixa recomendada pela OIC. Entretanto, a OIC não especifica para qual espécie de café é a faixa recomendada e nenhum dos autores informa a metodologia de avaliação do pH utilizada. Fatores como o método de extração do café, a concentração de gramas de café por mililitros de água e a temperatura de medição influenciam os valores de $\mathrm{pH}$ e podem ter acarretado as diferenças entre as faixas de $\mathrm{pH}$ recomendadas pelos autores. Dessa forma, a falta de tais informações torna difícil a escolha da melhor faixa de $\mathrm{pH}$ para uma comparação mais precisa com os dados obtidos no presente estudo.
Dentre as formas de processamento, o café natural é o que está mais susceptível à ocorrência de fermentações indesejadas. A acidez e o pH são indicadores de eventuais mudanças devido a essas fermentações. No presente trabalho, as etapas póscolheita do café natural, do café descascado e do café despolpado foram realizadas de maneira a garantir um produto final dentro dos padrões de qualidade, sem a ocorrência de fermentações indesejadas, o que pode explicar os resultados encontrados, não havendo diferenças nas médias de $\mathrm{pH}$ e acidez titulável total devido à forma de processamento (Tabela 1).

De acordo com a portaria $\mathrm{n}^{\circ} 377$, de 26 de abril de 1999 (BRASIL, 1999), o café torrado deve conter um teor mínimo de extrato aquoso de 25 $\%(\mathrm{~g} / 100 \mathrm{~g})$. Os teores de extrato aquoso do café natural e descascado encontram-se de acordo com a legislação; já o café despolpado apresentou valor abaixo do estipulado. O teor de extrato aquoso do café natural está próximo ao do café conilon natural submetido a torra média estudado por Ferreira Junior e Morais (2007).

$\mathrm{O}$ menor teor de extrato aquoso encontrado no café despolpado, quando comparado ao café natural e ao descascado, pode ser explicado em virtude da perda de massa que ocorre devido ao metabolismo normal, à respiração e à exosmose. No processamento via úmida com fermentação os grãos 
permanecem úmidos e vivos por um maior período de tempo, apresentando maiores perdas de massa devido ao metabolismo normal e à respiração, quando comparados aos grãos processados via seca. Além disso, durante a fermentação, ocorre perda de soluto do grão para a solução de fermentação. As perdas de massa associadas com a fermentação podem variar de $0,5 \%$ a $6,0 \%(9,0 \%$ em casos extremos), dependendo das temperaturas locais e do número de horas necessárias para a fermentação (BRANDO, 2004).
De acordo com os julgadores profissionais, a classificação da bebida quanto à pureza informa a ocorrência de sabores e, ou odores estranhos. Os resultados mostram que, independente da forma de processamento, o plantio e as etapas pós colheita foram realizados adequadamente, gerando um produto final livre de odores e sabores estranhos (Tabela 2).

Tabela 2. Caracterização sensorial das amostras.

\begin{tabular}{lccc}
\hline Atributo Sensorial & Natural & Descascado & Despolpado \\
\hline Pureza & Limpo & Limpo & Limpo \\
Gosto doce & Leve & Leve & Leve \\
Gosto conilon & Médio & Suave & Médio \\
Corpo & Médio & Médio & Pouco \\
Acidez & Média & Média & Alta \\
Adstringência & Maior & Menor & Menor \\
Nota global* & $7,3 \pm 0,04$ & $7,5 \pm 0,14$ & $7,4 \pm 0,14$ \\
\hline
\end{tabular}

*Média \pm desvio-padrão.

Fonte: Elaboração dos autores.

O café despolpado gerou uma bebida menos encorpada que as demais. Uma vez que existe uma relação entre o teor de extrato aquoso e o corpo da bebida, esse resultado foi condizente ao encontrado nas análises físico-químicas para extrato aquoso.

Bebidas preparadas a partir de café descascado apresentam a vantagem, em relação ao café despolpado, de possuir características de corpo semelhante às bebidas preparadas com café natural, produzindo bebidas mais encorpadas, indispensáveis à indústria de café solúvel (PIMENTA, 2003). Os resultados encontrados são condizentes com essa afirmação (Tabela 2).

Todas as amostras apresentaram a mesma intensidade de gosto doce e o café despolpado obteve uma acidez ligeiramente maior que as outras amostras. Essa diferença de acidez não foi observada na análise físico-química, sendo considerada estatisticamente igual às outras amostras (Tabela 1).
De acordo com a escala sensorial para café (ABIC, 2010), as amostras de café das três formas de processamento podem ser classificadas como cafés gourmet, recebendo nota global maior ou igual a 7,3 (Tabela 2). O café descascado apresentou a maior nota global e o café natural a menor. Essa diferença pode ter ocorrido devido ao suave gosto conilon encontrado no café descascado e à maior adstringência na bebida do café natural.

\section{Conclusão}

A utilização de matéria prima de boa qualidade, o processamento de apenas grãos cereja e realização adequada das etapas pós colheita, evitando a ocorrência de processos fermentativos indesejados, possibilitam a obtenção de um produto final dentro dos padrões de qualidade, com ótima nota global e sem alterações de $\mathrm{pH}$ e acidez, independente da 
forma de processamento utilizada. Na realidade, a grande vantagem do processamento via úmida está na utilização de apenas grãos cereja e na maior facilidade de se evitar processos fermentativos indesejados. Entretanto, o presente trabalho permitiu demonstrar que é possível obter bebida encorpada e dentro dos padrões de qualidade utilizando a forma de processamento via seca (café natural), processamento menos custoso que os demais, desde que sejam processados apenas grãos cereja e que seja evitada a fermentação indesejada do café.

\section{Agradecimentos}

Os autores agradecem ao INCAPER (Instituto Capixaba de Pesquisa, Assistência Técnica e Extensão Rural) pela doação das amostras de café.

\section{Referências}

ASSOCIAÇÃO BRASILEIRA DA INDÚSTRIA DE CAFÉ -ABIC. Nível mínimo de qualidade licitações orientações. 2010. Disponível em: <http://www.abic. com.br/publique/cgi/cgilua.exe/sys/start.htm?sid=17>. Acesso em: 21 nov. 2011.

Norma de qualidade recomendável e boas práticas de fabricação de cafés torrados em grão e cafés torrados e moídos. 2012. Disponível em: <http:// www.abic.com.br/publique/media/Norma $\% 20 \mathrm{de} \% 20$ qualidade.pdf $>$. Acesso em: 13 nov. 2012.

BALZER, H. H. Acids in coffee. In: CLARKE, R. J.; VITZTHUM, O. G. (Ed.). Coffee: recent developments. London: Blackwell Science, 2001. cap. 1B, p. 18-32.

BRANDO, C. H. J. Harvesting and green coffee processing. In: WINTGENS, J. N. (Ed.). Coffee: growing, processing, sustainable production: A guidebook for growers, processors, traders, and researchers. Weinheim: Wiley-VCH Verlag GmbH \& Co. KGaA, 2004. Part 3, cap. 2, p. $604-715$.

BRASIL. Agência Nacional de Vigilância Sanitária. Portaria $n^{\circ} 377$, de 26 de abril de 1999. Aprova o regulamento técnico para fixação de identificação e qualidade de café torrado em grão e café torrado e moído. Brasília, 1999. Disponível em: <http://www.anvisa.gov. br/legis/portarias/377 99.htm>. Acesso em: 21 nov. 2012.
- Ministério da Agricultura, Pecuária e Abastecimento. Instrução normativa $n^{\circ} 8$, de 11 de junho de 2003. Aprova o regulamento técnico de identidade e de qualidade para a classificação do café beneficiado grão cru. Brasília, 2003. Disponível em: <http://www. abic.com.br/publique/media/NMQ_LEGISLAcaO_IN8. pdf $>$. Acesso em: 21 nov. 2011.

Ministério da Agricultura, Pecuária e Abastecimento. Instrução normativa $n^{\circ} 16$, de 24 de maio de 2010. Aprova o regulamento técnico para o café torrado em grão e para o café torrado e moído. Brasília, 2010. Disponível em: < http://www.sindicafesp.com. br/arquivos/sindi_leg_regulamentotecnicoIN16.pdf $>$. Acesso em: 12 nov. 2012.

CENTRO DE DESENVOLVIMENTO TECNOLÓGICO DO CAFÉ - CETCAF. Estudo de qualidade dos diferentes tipos de café conilon produzidos no ES. 2006. Disponível em: <http://www.cetcaf.com.br/padrao\%20 bebida $\% 20$ conilon/projeto\%20padraobebidaconilon. htm>. Acesso em: 12 nov. 2012.

CLIFFORD, M. N. Chemical and physical aspects of green coffee and coffee products. In: CLIFFORD, M. N.; WILLSON, K. (Ed.). Coffee: botany, biochemistry and production of beans and bevarage. London \& Sydney: CROOM HELM, 1985. cap. 13.

DELLA LUCIA, S. M.; MINIM, V. P. R.; CARNEIRO, J. C. S.; CARNEIRO, J. D. S. Aplicação da análise descritiva quantitativa para a caracterização sensorial de produtos alimentícios. In: TEIXEIRA, L. J. Q.; ALMEIDA, M. F. L.; DELLA LUCIA, S. M.; TOSTES, M. G. V. (Org.). Ciência de alimentos, nutrição e saúde: avanços e perspectivas. Alegre, ES: CCA-UFES, 2009. cap. 10, p. 139-154.

FERREIRA JÚNIOR, M. F.; MORAIS, S. A. L. Estudo da composição química do café conilon (C. canephora) proveniente do cerrado mineiro. Revista Horizonte Cientifico, Uberlândia, v. 1, n. 1, p. 1-23, 2007.

INSTITUTO ADOLFO LUTZ - IAL. Métodos fisicoquímicos para análise de alimentos. 4. ed. São Paulo: Instituto Adolfo Lutz, 2008. 1020 p. (Versão eletrônica).

JACINTHO, M. I. M. Efeito do modo de preparo na composição química de grãos de café cru e torrado. Relação da composição química com a qualidade da bebida. 2002. Dissertação (Mestrado em Ciência de Alimentos) - Universidade Estadual de Campinas, Campinas. 
MENDES, L. C. Estudos para determinação das melhores formulações de blends de café arábica (C. arabica) com café robusta (C. canephora Conilon) para uso no setor de cafés torrados e moídos e de cafés espresso. 2005. Tese (Doutorado em Tecnologia de Alimentos) - Universidade Estadual de Campinas, Campinas.

OIC. Trade statistic. 1992. Disponível em: <http://www. ico.org/trade_statistics.asp >. Acesso em: 21 out. 2011.

PIMENTA, C. J. Qualidade de café. 3. ed. Lavras: Editora UFLA, 2003. 304 p.

RIBEIRO JÚNIOR, J. I. Análises estatísticas no SAEG. Viçosa: UFV, 2001. 301 p.
SALVA, T. J. G. A Composição química do grão e a qualidade da bebida em conseqüência do método de preparo e cultivar. In: SALVA, T. J. G.; GUERREIROFILHO, O.; THOMAZIELLO, R. A.; FAZUOLI, L. C. (Org.). Cafés de qualidade: aspectos tecnológicos, científicos e comerciais. Campinas SP: Instituto Agronômico, 2007. v. 1, p. 255-280.

SPECIALTY COFFEE ASSOCIATION OF AMERICA - SCAA. SCAA protocols. 2009. Disponível em: <http:// www.scaa.org/PDF/resources/cupping-protocols.pdf $>$. Acesso em: 13 nov. 2012. 